\title{
Editorial
}

\section{As Others See Us?}

One of the more encouraging features of the International Year of the Child has been the belated realization that it might be a good idea to ask childrens' opinions on the world they experience - a world largely created by adults. Too often we assume that we know what children like and what they think. A few minutes talking with a child - instead of talking at him - usually gives a different picture, revealing a remarkable degree of critical awareness about the ambiguities and double standards of the adult world. Not any child of course, but one who has not been sedated by a massive diet of mindless television, hectored by a regiment of authoritarian teachers, or stereotyped by his own parents. For these are not really children as they should be if we recognised their need for individual care and nurturing. They are instead a species of homunculi, miniature adults deprived of their one and only chance to be themselves. Listen to them talking - they are ourselves, parroting the spurious values of a consumer dominated society; oppressed by the adult world.

This pessimistic view of the childhood experiences of some children is shared by Dr Shelley Phillips, whose recent book, "Young Australians - The Attitudes of our Children"' urges adults to be more understanding of children - from the child's point of view. In making the link between oppressed children and repressive adults (including parents) she is making a local link in an international chain of research findings. Her research, carried out in Sydney, found a high percentage of children with basically authoritarian attitudes which seem to mirror those of the adult world. We should not, of course, be surprised at this. Their sex role stereotyping, racial attitudes, lack of trust and the significant authoritarianism of boys should, however, be a major cause for concern. The other side of the coin is also presented: it should give us grounds for hope that many adults and parents do understand and are able to create an environment for growth, creativity and co-intellectual curiosity. Phillips says "Children from fair and understanding families tend to be more independent. They are able to assume responsibility for their own behaviour and are friendly in interaction with adults as they have not been taught to fear or mistrust them." In other words, they have been allowed to develop as individuals.

Childhood should be cherished and safeguarded. It is a once and never to be repeated opportunity to hopefully experience life's diversity and richness within the context of loving and trusting relationships with adults. If we, the adults, betray that trust in the pursuit of our own selfishness or greed, we deprive our children of part of their capacity to make their own significant relationships. We must try harder to let children show us how we appear to them.

Burns was right -

"O wad some Pow'r the giftie gie us

To see oursels as others see us!

It wad frae mony a blunder free us,

And foolish notion."

Part and parcel of this whole exercise entails seeing children as individuals and treating them as such - not merely giving lip service to the notion. Recently my own children were given an example of how adults get it wrong by thinking they know the answers. A whole programme of activities for children was organised by a group of adults. Said Sian, aged 13, and Mark, aged 10, "You'd think that at least in the Year of the Child some children could have been on the committee." Enough said.

Cliff Picton. 